\title{
OPEN Soil zinc, serum zinc, and the potential for agronomic biofortification to reduce human zinc deficiency in Ethiopia
}

\begin{abstract}
Hugo De Groote $\mathbb{1}^{1 凶}$, Masresha Tessema $\mathbb{1}^{2,3,4}$, Samuel Gameda $\mathbb{\circledR}^{5}$ \& Nilupa S. Gunaratna $\mathbb{1}^{6}$
Human zinc deficiency is a global public health problem. Many African soils are zinc deficient (ZnD), indicating fertilizers could increase crop yields and grain Zn levels, thereby increasing $Z n$ in the food supply and alleviating human $\mathrm{Zn}$ deficiency. To analyze associations among soil $\mathrm{Zn}$, human $\mathrm{Zn}$ deficiency, and child nutritional status, we combined the Ethiopian soil Zn map and the Ethiopian National Micronutrient Survey (ENMS). ENMS provides representative, georeferenced data on child nutritional status using anthropometry of children under five years old (CU5) and on human Zn deficiency among CU5 and women of reproductive age (WRA) using the recommended biomarker, serum Zn. ZnD soils mostly occur in lower altitudes, which are less populated and outside the main crop-producing areas. Serum Zn deficiencies were high, and correlated to soil Zn for children, but not for WRA. About 4 million Ethiopian CU5 are ZnD, and, of these, about 1.5 million live on low-Zn soils ( $<2.5 \mathrm{mg} / \mathrm{kg}$ ), while 0.3 million live on $\mathrm{ZnD}$ soils $(<1.5 \mathrm{mg} / \mathrm{kg})$. Therefore, if $Z \mathrm{n}$ fertilizers are only applied on $Z n D$ soils, their impact on child $Z n$ deficiency may be limited. Greater impact is possible if $\mathrm{Zn}$ fertilizers are applied to soils with sufficient $\mathrm{Zn}$ for plant growth and if this results in increased grain $\mathrm{Zn}$. Optimal soil Zn levels for plant and human nutrition may be different, and context-specific optimal levels for the latter must be determined to develop nutrition-sensitive fertilizer policies and recommendations.
\end{abstract}

Undernutrition due to micronutrient deficiencies is prevalent in developing countries ${ }^{1,2}$. Human zinc deficiency, for example, is a global public health problem with important consequences for human health ${ }^{3-5}$. Mapping of soil fertility in Africa has shown zinc ( $\mathrm{Zn})$ deficiency to also be common in soils ${ }^{6}$, leading to the hypothesis that $\mathrm{Zn}$-containing fertilizers could contribute to increased crop yields as well as increased grain $\mathrm{Zn}$ levels, which could then reduce human $\mathrm{Zn}$ deficiency by increasing the availability of $\mathrm{Zn}$ in the food supply ${ }^{7}$. This process is called agronomic biofortification ${ }^{8}$, in which crops can be "fortified" through agronomic means, and is similar to genetic biofortification", in which the nutritional content of crops is increased through plant breeding. For agronomic biofortification to be successful, there must be a causal link between soil $\mathrm{Zn}$ and human $\mathrm{Zn}$ status in target populations, and $\mathrm{Zn}$-deficient soils and $\mathrm{Zn}$-deficient human populations must geographically coincide.

Zinc is a trace element essential for all life forms. It is involved in the production of a wide range of enzymes and proteins in plants, animals, and humans ${ }^{10}$. Recognition of its importance in human nutrition came relatively late ${ }^{11}$, but $\mathrm{Zn}$ deficiency is now considered an important public health issue, especially in developing countries ${ }^{12}$. It affects a range of health outcomes, including increased risk of mortality, stunting, diarrhea, and respiratory illnesses in children, preterm delivery in pregnant women, and immune function ${ }^{13-15}$.

Zinc deficiency in soils is an important constraint to crop production, and the most ubiquitous micronutrient deficiency in crops worldwide ${ }^{10}$, particularly limiting yields in developing countries ${ }^{16,17}$. Adding $\mathrm{Zn}$ to fertilizers is therefore a common strategy to enhance plant growth and increase yield ${ }^{17}$. Maize is the cereal most susceptible to $\mathrm{Zn}$ deficiency, although wheat and rice can also be highly prone ${ }^{10}$. In Ethiopia, a recent soil-fertility mapping exercise showed over $50 \%$ of agricultural soils to be $\mathrm{Zn}$ deficient, reaching over $70 \%$ in the Tigray region ${ }^{18}$. Diammonium phosphate (DAP) and urea have been the main fertilizers used in Ethiopia, supplying only two

\footnotetext{
${ }^{1}$ International Maize and Wheat Improvement Center (CIMMYT), PO Box 1041-00621, Nairobi, Kenya. ${ }^{2}$ Ethiopian Public Health Institute, Gulelle Arbegnoch Street, Gulele Sub City, Addis Ababa, Ethiopia. ${ }^{3}$ Wageningen University, Wageningen, The Netherlands. ${ }^{4}$ Jimma University, Jimma, Ethiopia. ${ }^{5}$ CIMMYT Ethiopia, P.O. Box 5689, Addis Ababa, Ethiopia. ${ }^{6}$ Department of Public Health, Purdue University, 812 W State St., West Lafayette, IN 47907-2059, USA. ${ }^{\circledR}$ email: h.degroote@cgiar.org
} 


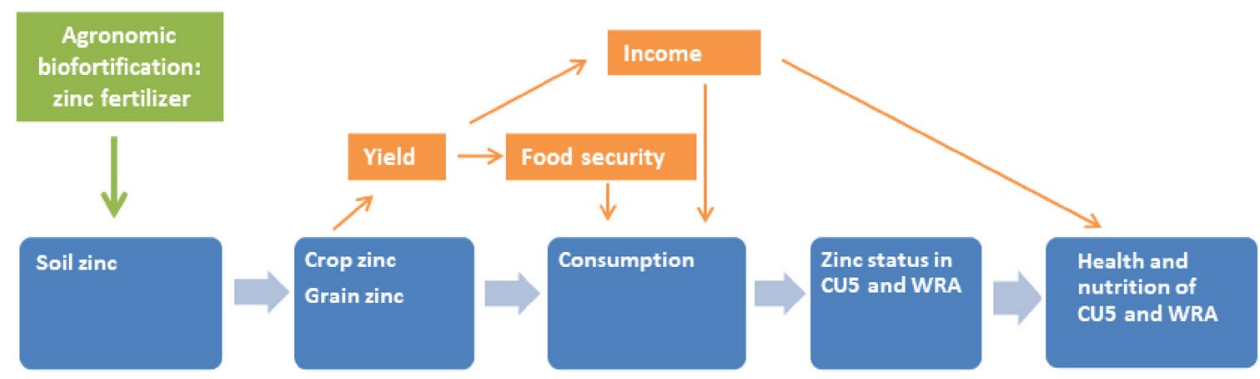

Figure 1. Conceptual framework of the potential impact of zinc agronomic biofortification of maize. (CU5: children under five years of age, WRA: women of reproductive age).

nutrients, phosphorus and nitrogen, while deficiencies in as many as eight nutrients, including Zn, were shown, leading to a national commitment to use blended fertilizers, i.e., fertilizers containing multiple nutrients, to address these deficiencies.

Human zinc requirements are relatively small, with $8 \mathrm{mg} /$ day recommended for women and $11 \mathrm{mg} / \mathrm{day}$ recommended for men ${ }^{19}$. Still, an estimated $17.3 \%$ of the global population is at risk of insufficient $\mathrm{Zn}$ in their $\operatorname{diet}^{20}$, the main causes being insufficient intake or inadequate absorption ${ }^{21,22}$. Foods based on unrefined cereals and legumes tend to contain high levels of phytate, a potent inhibitor of $\mathrm{Zn}$ absorption ${ }^{23}$. In sub-Saharan Africa, where such diets are common, $\mathrm{Zn}$ deficiency is high ${ }^{5,22}$. Risk of $\mathrm{Zn}$ deficiency becomes a public health concern when the prevalence of inadequate $\mathrm{Zn}$ intake is higher than $25 \%{ }^{24}$.

Ethiopia has particularly high rates of malnutrition and of adverse health outcomes associated with $\mathrm{Zn}$ deficiency: child mortality, morbidity, and stunting, and adverse perinatal outcomes in women ${ }^{25-27}$. Recent studies have quantified the burden of Zn deficiency in Ethiopia ${ }^{3,28-31}$. In $2011,92 \%$ of children aged $1-3$ years and $61 \%$ of adult women of reproductive age (WRA) had inadequate dietary intakes of $\mathrm{Zn}^{32}$.

Ideally, all people should have access to and consume a wide range of nutritious foods to fulfill their dietary needs; however, until that is achieved, complementary approaches are needed. Supplements and fortification of staple foods with micronutrients are common, but they reach the urban population more easily than the rural population, even though the latter are more affected ${ }^{33}$. Staple foods biofortified with micronutrients ${ }^{34}$ are an interesting alternative approach to reach rural populations, who have more limited access to diverse diets and nutritional interventions ${ }^{9,35,36}$. Genetic biofortification has resulted in increased provitamin A in orange-fleshed sweet potatoes ${ }^{37}$ and in orange maize ${ }^{38}$, and also led to high-iron beans ${ }^{39}$, and high-zinc and -iron durum wheat ${ }^{40}$.

For mineral micronutrients, agronomic biofortification can also help. In Finland, fortification of fertilizers with sodium selenite increased the selenium (Se) intake of the whole population, eliminating deficiencies ${ }^{41,42}$. Zinc fertilizer is used to increase yields on $\mathrm{Zn}$ deficient soils and has been particularly successful on wheat in Turkey $^{43}$; it can also increase $\mathrm{Zn}$ in cereal grain ${ }^{44,45}$. Zinc fertilizer applied to maize has high potential for Africa ${ }^{7}$, and in particular for Ethiopia, where human $\mathrm{Zn}$ deficiency is high, soils are $\mathrm{Zn}$-deficient, and maize has become the major food crop.

While agronomic biofortification can increase yields and increase micronutrient content of staple crops, this does not necessarily lead to improved human health ${ }^{46}$. The link between soil $\mathrm{Zn}$ and human $\mathrm{Zn}$ status, in particular, is not well understood. Recently, weak associations were found between soil nutrients, including $\mathrm{Zn}$, and some health indicators, including child mortality and stunting in Sub-Saharan Africa ${ }^{47}$. In India, soil $\mathrm{Zn}$ affected $\mathrm{Zn}$ levels in rice and thus in the diet, but associations were not observed with serum $\mathrm{Zn}^{48}$. In Ethiopia, using the soil Zn map and the Ethiopian National Micronutrient Survey (ENMS), a significant correlation was found between soil $\mathrm{Zn}$ and serum $\mathrm{Zn}^{49}$. However, none of these observational studies provide strong evidence of causal relationships between soil $\mathrm{Zn}$ and human $\mathrm{Zn}$ status. Moreover, for agronomic biofortification with $\mathrm{Zn}$ to benefit human health, $\mathrm{Zn}$ deficient populations must live on $\mathrm{Zn}$ deficient soils, on which $\mathrm{Zn}$ fertilizer is applied and $\mathrm{Zn}$ in the harvested food supply is increased and consumed. It is not known whether these conditions could be met in Ethiopia or other countries that are potential targets for $\mathrm{Zn}$ agronomic biofortification (ZAB). Therefore, to help fill this gap, this research has the following objectives: (i) to map the geographic codistribution of $\mathrm{Zn}$ deficiency in soils and in children under 5 years, a target population particularly vulnerable to $\mathrm{Zn}$ deficiency, (ii) to quantify the potential impact of ZAB by calculating the number of $\mathrm{Zn}$-deficient children living on $\mathrm{Zn}$-deficient soils in crop-growing areas, and (iii) to analyze the geographic distribution of that impact to inform nutrition-sensitive $\mathrm{ZAB}$ policies.

\section{Methods}

Conceptual framework and overview. Conceptually, a direct link between low $\mathrm{Zn}$ in the soil and adverse health effects in humans can be hypothesized as follows (Fig. 1, direct effects in blue). Low soil $\mathrm{Zn}$ results in reduced plant growth and crop yields and low $\mathrm{Zn}$ levels in cereal grain ${ }^{44}$ and, when these comprise a substantial part of a diet low in alternative $\mathrm{Zn}$ sources, to low dietary $\mathrm{Zn}$ intake ${ }^{48}$. This leads to poor $\mathrm{Zn}$ status, and infants, young children, and women of reproductive age are particularly vulnerable, with associated adverse effects on health outcomes ${ }^{3,30,50}$. Zinc agronomic biofortification increases both yields and grain $\mathrm{Zn} \mathrm{levels}{ }^{44,51}$, which could then result in higher overall dietary $\mathrm{Zn}$ intake, and improved zinc status in women and children 


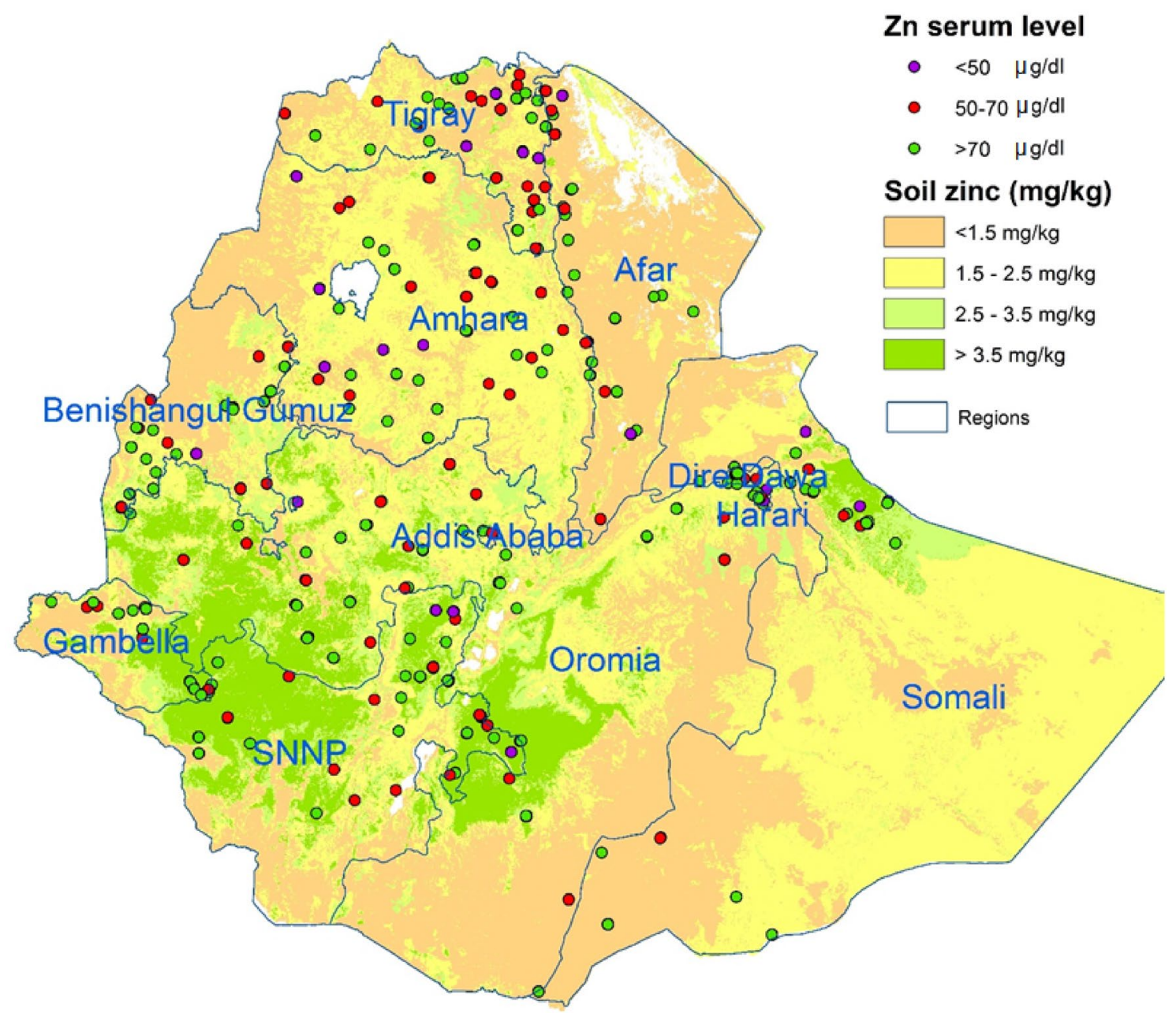

Figure 2. Map with soil zinc levels (AfSIS) and serum Zn levels in children under five years (ENMS) (map produced with ArcGIS Desktop version 10.8.1 from ESRI, https://www.esri.com/en-us/arcgis/products/arcgisdesktop/overview).

(Fig. 1). Finally, higher Zn status can improve health outcomes. Increasing yields can also improve food security and/or income, indirectly improving health and nutrition outcomes (Fig. 1, indirect effects in orange).

To analyze these conceptualized relationships, we overlaid the soil zinc map from the African Soil Information System (AfSIS) ${ }^{6}$ with the Ethiopian National Micronutrient Survey (ENMS) ${ }^{31}$. Further, we combined these maps with the crop map and the population map to calculate the number of potential beneficiaries of ZAB on different soil types and regions of Ethiopia.

Data sources and analysis. The soil zinc map of Ethiopia, based on systematic soil samples taken over most of Ethiopia, was obtained from the Africa Soil Information System (AfSIS, http://africasoils.net) (Fig. 2). This map represents extractable $\mathrm{Zn}$ levels as measured by the Mehlich 3 extraction method ${ }^{52}$. Zinc-deficient soils are defined as having extractable $\mathrm{Zn}$ levels lower than $1.5 \mathrm{mg} / \mathrm{kg}^{53}$, and soils with low Zn levels as those with levels between 1.5 and $<2.5 \mathrm{mg} / \mathrm{kg}$. AfSIS also provided a crop mask: a grid layer indicating where crops were grown, developed with a machine-learning algorithm based on open source data ${ }^{54}$.

Data on Zn levels in human serum were obtained from the Ethiopia National Micronutrient Survey (ENMS), in which 3,805 households participated, randomly selected to be representative of the country's regions. In these households, blood samples were collected from 1,776 children under five (CU5, aged between 6 and 59 months, of which 52\% were girls), and 1,191 women of reproductive age (WRA, aged between 15 and 49 years old). From these, ENMS analyzed the serum Zn in 1,171 CU5 (Fig. 2) and 1,181 WRA.

The population of Ethiopia was obtained from the World Population layer (2015, http://www.worldpop.org. $\mathrm{uk} /$ ), which is based on national census data and adjusted so that the totals reflect the national estimates. This data base has a layer of male and female CU5 (15.37\% of the total), and a layer of WRA, estimated as those from 15 to 49 years old $(24.81 \%)$.

Analysis. As the ENMS data are representative at the regional level (the highest administrative level in Ethiopia), representative regional averages can be calculated and multiplied with regional populations to calculate the number of $\mathrm{Zn}$-deficient people. As the ENMS data were georeferenced, the soil $\mathrm{Zn}$ levels for each data point 


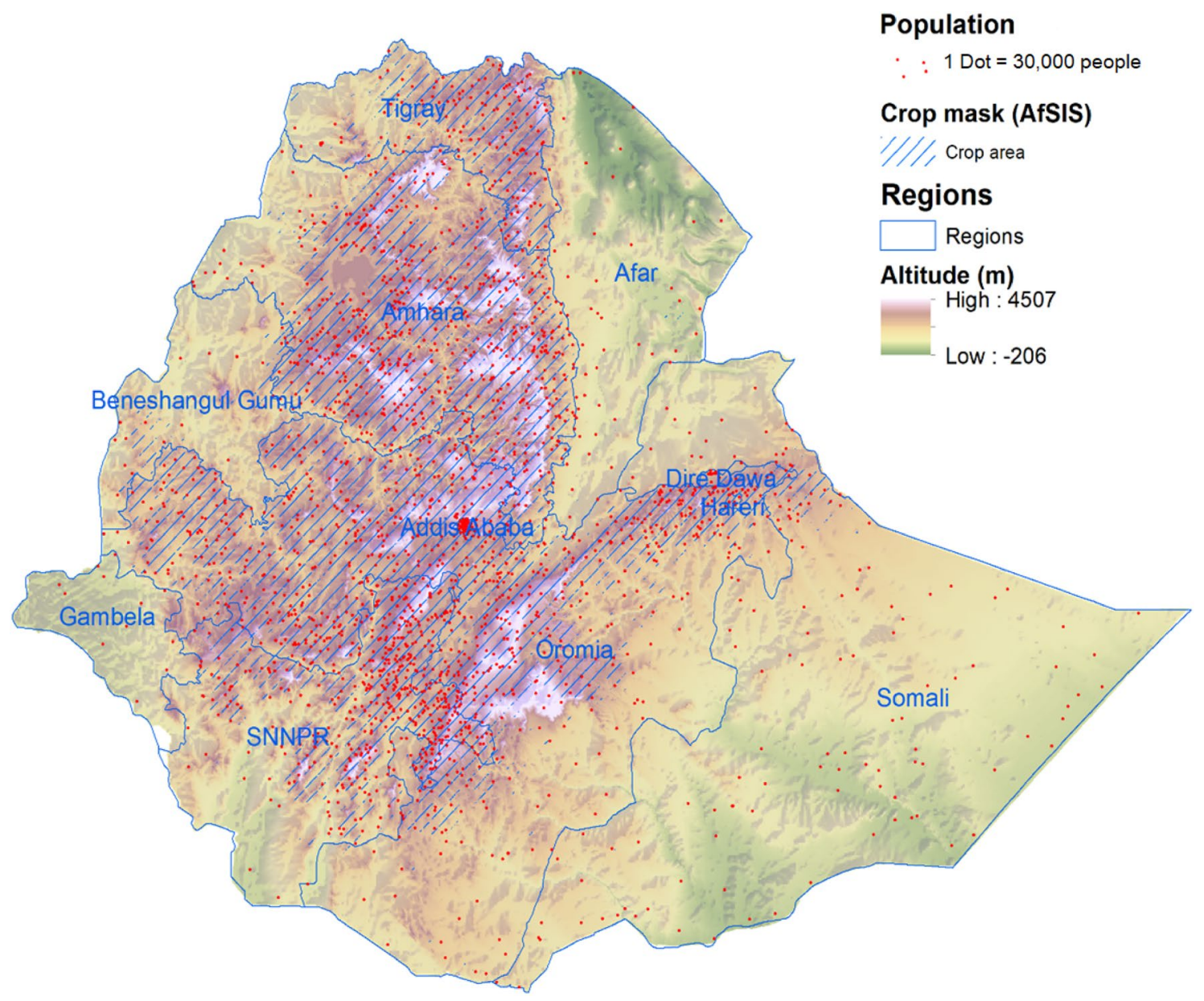

Figure 3. Population, altitude and crops in Ethiopia (map produced with ArcGIS Desktop version 10.8.1 from ESRI, https://www.esri.com/en-us/arcgis/products/arcgis-desktop/overview).

could be extrapolated from the soil $\mathrm{Zn}$ map. The link between soil $\mathrm{Zn}$ and serum $\mathrm{Zn}$ was then analyzed, using serum $\mathrm{Zn}$ level and $\mathrm{Zn}$ deficiency as dependent variables and soil $\mathrm{Zn}$ level as an exploratory variable. Ordinary linear regression was used to analyze the effect of soil $\mathrm{Zn}$ (in $\mathrm{mg} / \mathrm{kg}$ ) on serum $\mathrm{Zn}$ (in $\mu \mathrm{g} / \mathrm{dL}$ ). Logistic regression was used to estimate the effect of soil $\mathrm{Zn}$ on the probability of a person being $\mathrm{Zn}$-deficient, defined as serum $\mathrm{Zn}<65 \mu \mathrm{g} / \mathrm{dL}$ for children (morning, non-fasting) and $<70 \mu \mathrm{g} / \mathrm{dL}$ for adult women (morning, fasting) ${ }^{55}$. The association was only significant for children, not for women, so only children were retained for further analysis.

Next, the serum Zn levels of children were extrapolated using Bayesian Kriging in ArcGIS Desktop (version 10.8.1 from ESRI, https://www.esri.com/en-us/arcgis/products/arcgis-desktop/overview) to produce a countrywide layer of the probability of $\mathrm{Zn}$ deficiency for children. This layer was then multiplied with the population layer to map the number of $\mathrm{Zn}$-deficient children. By overlaying the resulting layer with the crop mask and the soil map, the number of $\mathrm{Zn}$-deficient children living on agricultural soils, either $\mathrm{Zn}$-deficient or with low $\mathrm{Zn}$ levels, could be calculated.

Ethics approval. This study only uses secondary data: soil maps were obtained from AfSIS, and ENMS data were obtained from the Ethiopian Public Health Institute (EPHI), without identifiable variables such as names of the household members or participants. Ethical clearance for the ENMS was obtained from the National Research Ethical Review Committee of the Ethiopian Science and Technology Ministry (number 3.10/433/06), and informed consent was obtained from all adults who were interviewed, specifically the household head and caregiver, who also consented to the participation of their children. All methods were performed in accordance with the relevant guidelines and regulations.

\section{Results}

Population distribution. Before conducting our analysis of soil- and serum $\mathrm{Zn}$, it was important to understand the population distribution in Ethiopia, as this would substantially affect the interpretation of the results. As shown in Fig. 3, the geography of Ethiopia is dominated by the Great Rift Valley, which transects the country from the South West to the North East, with highland areas on both sides. The SE highlands are narrow, located mostly in Oromia and partly in the Southern Nations, Nationalities and People's region (SNNPR), while the NW highlands form a wide stretch and cover most of western Oromia, some parts of SNNPR, most of Amhara and 


\begin{tabular}{|c|c|c|c|c|c|c|}
\hline Group & Model & Dependent variable & Independent variables & Coefficient & Std. error & Sig \\
\hline \multirow{4}{*}{ Children $(\mathrm{N}=1038)$} & \multirow{2}{*}{ Linear model } & \multirow{2}{*}{ Serum $\mathrm{Zn}(\mu \mathrm{g} / \mathrm{dL})$} & Constant & 74.994 & 1.044 & $<0.001$ \\
\hline & & & Soil Zn (mg/kg) & 0.693 & 0.282 & 0.014 \\
\hline & \multirow{2}{*}{ Logistic model } & \multirow{2}{*}{$\begin{array}{l}\text { Zn deficiency (serum } \\
\mathrm{Zn}<65 \mu \mathrm{g} / \mathrm{dL} \text { ) }\end{array}$} & Constant & -0.668 & 0.143 & $<0.001$ \\
\hline & & & Soil Zn (mg/kg) & -0.145 & 0.047 & 0.002 \\
\hline \multirow{4}{*}{$\begin{array}{l}\text { Women of reproductive } \\
\text { age }(\mathrm{N}=1191)\end{array}$} & \multirow{2}{*}{ Linear model } & \multirow{2}{*}{ Serum $\mathrm{Zn}, \mu \mathrm{g} / \mathrm{dL}$} & Constant & 82.309 & 1.068 & $<0.001$ \\
\hline & & & Soil Zn (mg/kg) & -0.267 & 0.320 & 0.405 \\
\hline & \multirow{2}{*}{ Logistic model } & \multirow{2}{*}{$\begin{array}{l}\text { Zn deficiency (serum } \\
\mathrm{Zn}<70 \mu \mathrm{g} / \mathrm{dL} \text { ) }\end{array}$} & Constant & -0.706 & 0.092 & $<0.001$ \\
\hline & & & Soil Zn (mg/kg) & 0.021 & 0.027 & 0.448 \\
\hline
\end{tabular}

Table 1. Regression of serum zinc and zinc deficiency of children on soil zinc (all models estimated with random effects of the cluster variable, the 247 enumeration areas of the ENMS).

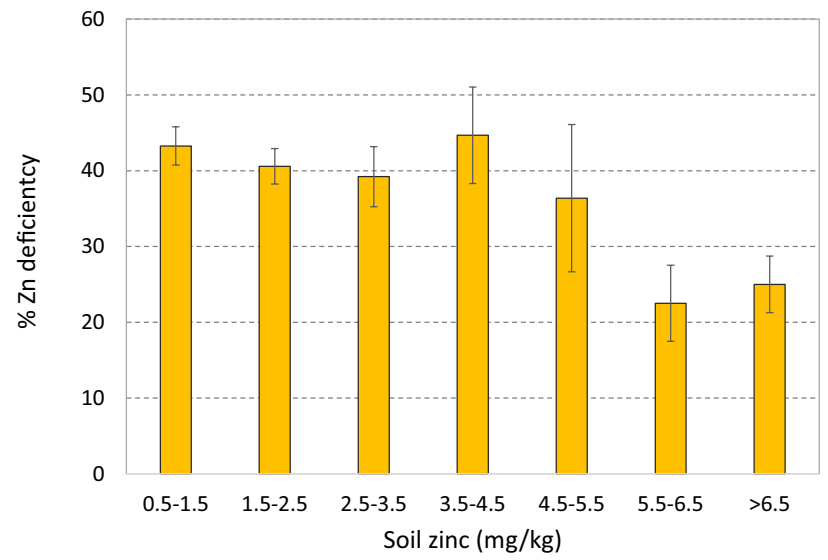

Figure 4. Zinc deficiency in children, by soil zinc level category (error bars are 95\% confidence intervals).

a large part of Tigray. Almost all agricultural production takes place in these areas, and most of the population live there, including 9 million CU5 (out of 13.4 million).

Analyzing the link between soil zinc and serum zinc. The soil map of Ethiopia shows that $\mathrm{Zn}$-deficient soils $(\mathrm{Zn}<1.5 \mathrm{mg} / \mathrm{kg})$ are mostly found in the lower altitudes, located around, but not in, the highlands, which constitute the main agricultural areas in Ethiopia, except for some highland areas in Amhara and Tigray (Fig. 2). Low-Zn soils $(1.5<\mathrm{Zn}<2.5 \mathrm{mg} / \mathrm{kg})$, on the other hand, cover a large part of northern and south-eastern Ethiopia, including most of Tigray and Amhara.

Children and women from the ENMS survey were defined as $\mathrm{Zn}$-deficient when their serum $\mathrm{Zn}$ was below 65 and $70 \mu \mathrm{g} / \mathrm{dL}$, respectively, and severely Zn-deficient if it was below $50 \mu \mathrm{g} / \mathrm{dL}$. The average serum Zn level for children per cluster is presented in Fig. 2. The results show a high level of human $\mathrm{Zn}$ deficiency throughout the country, with weighted estimates of $28 \%$ of CU5 and $34 \%$ of WRA.

As the ENMS households were georeferenced, their position could be overlaid with the soil map and the interpolated soil $\mathrm{Zn}$ levels at these locations extracted. Analysis shows a significant positive correlation between serum $\mathrm{Zn}$ and soil $\mathrm{Zn}$ for children under five (Spearman's $\rho=0.083, p=0.006$ ), but not for women of reproductive age. The results also show a significant correlation for children between soil $\mathrm{Zn}$ and weight-for-height $\mathrm{z}$-score (WHZ) $(\rho=0.084, p=0.001)$, but not between soil $\mathrm{Zn}$ and height-for-age $\mathrm{z}$-score (HAZ), contrary to expectation.

Similarly, regression analysis shows a significant association of soil Zn with serum $\mathrm{Zn}$ in CU5, but not in WRA (Table 1). The linear regression shows that soil Zn levels have a small but significant association with children's serum $\mathrm{Zn}$ levels: for each $\mathrm{mg} / \mathrm{kg}$ increase in soil $\mathrm{Zn}$ levels, serum $\mathrm{Zn}$ increases by $0.7 \mu \mathrm{g} / \mathrm{dL}$. Similarly, soil $\mathrm{Zn}$ levels significantly reduce the probability that a child is $\mathrm{Zn}$-deficient; with a coefficient (or log-odds ratio in this model) of -0.14 , indicating that for each $\mathrm{mg} / \mathrm{kg}$ increase of soil $\mathrm{Zn}$, the odds of a child being $\mathrm{Zn}$-deficient decrease by a factor of 0.87 , or $13 \%$ (1-0.87). In other words, at the mean soil $\mathrm{Zn}$ level $(2.7 \mathrm{mg} / \mathrm{kg})$, an increase of one $\mathrm{mg} / \mathrm{kg}$ leads to a decrease in child $\mathrm{Zn}$ deficiency of $2.8 \%$ (from 27.2 to $24.4 \%$ ). The effect of soil $\mathrm{Zn}$ levels on women's serum Zn levels or on the probability of women being Zn-deficient was, however, not significant.

Graphic analysis, however, indicates that the reduction of Zn deficiency in children due to soil Zn only kicks in at relatively high levels, around $4.5 \mathrm{mg} / \mathrm{kg}$ (Fig. 4). Therefore, children living on soils with Zn levels of $4.5 \mathrm{mg} / \mathrm{kg}$ or less are more likely to be $\mathrm{Zn}$-deficient (on average more than $40 \%$ ), while those on soils with $\mathrm{Zn}$ levels higher than $5.5 \mathrm{mg} / \mathrm{kg}$ or more are substantially less likely to be $\mathrm{Zn}$-deficient (around 20\%). For women of reproductive age, such a link is not clear. For children, on the other hand, the results indicate that there is potential for 


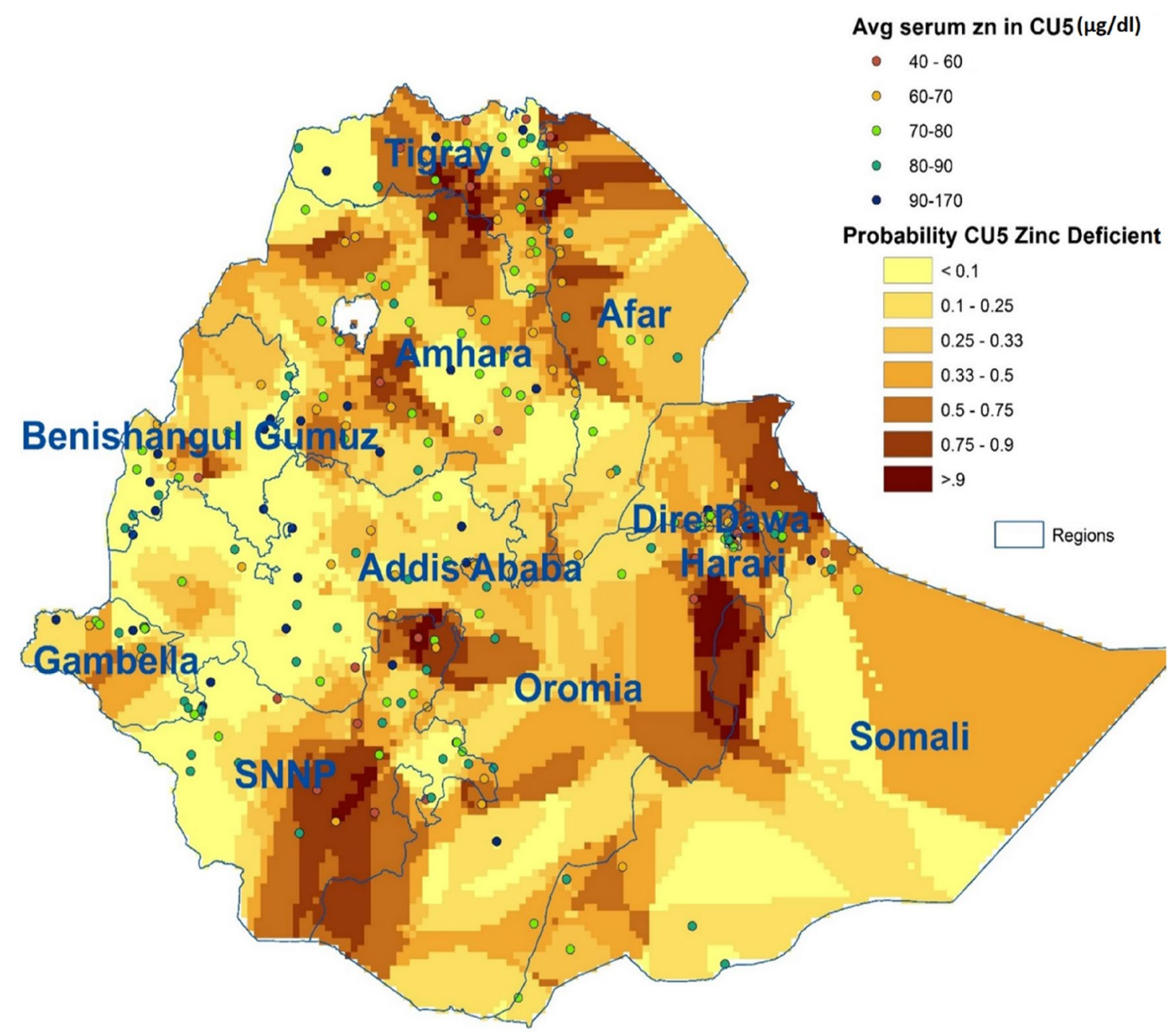

Figure 5. Average serum zinc in children under-five (per cluster, in $\mu \mathrm{g} / \mathrm{dL}$ ), and interpolated probability of zinc deficiency (serum zinc $<70 \mu \mathrm{g} / \mathrm{dL}$ ) (map produced with ArcGIS Desktop version 10.8.1 from ESRI, https://www. esri.com/en-us/arcgis/products/arcgis-desktop/overview).

reducing $\mathrm{Zn}$ deficiency in children by agronomic biofortification of soils that had enough $\mathrm{Zn}$ for plant nutrition, but not for child nutrition. While the results do not allow calculation of a precise cut-off, the cut-off for human nutrition is likely substantially higher than that for plant nutrition.

Calculating the number of potential beneficiaries. Based on the soil $\mathrm{Zn}$ levels from the AfSIS, the soils in Ethiopia can be divided into three categories: Zn-deficient $(<1.5 \mathrm{mg} / \mathrm{kg})$, low Zn $(1.5-2.5 \mathrm{mg} / \mathrm{kg})$ and sufficient Zn (>2.5 mg/kg) (Fig. 2). The average serum Zn levels of CU5, as obtained from the ENMS, were averaged over their clusters for clarity and added to the map. The map shows some higher levels of Zn deficiency in children on Zn-deficient and low-Zn soils, but not a strong link.

The individual serum $\mathrm{Zn}$ levels, georeferenced, were interpolated over the whole country using Bayesian kriging, resulting in a nation-wide geographic distribution of the probability of children under-five being Zndeficient (Fig. 5). This map shows clear areas with a high probability of children being Zn-deficient, and these areas are more prevalent on $\mathrm{Zn}$-deficient or low-Zn soils. Among agricultural areas, these include most of Tigray and large areas of Amhara and SNNPR, but not Oromia.

Next, the probability of Zn deficiency among children was multiplied by the actual number of children under five years of age (0-59 months) in each cell, resulting in a map of the number of Zn-deficient children (Fig. 6, Panel A). The results show high numbers of $\mathrm{Zn}$-deficient children in most agricultural and high populationdensity areas. When we calculate the number of $\mathrm{Zn}$-deficient children on low-Zn soils (Fig. 6, Panel B), clear areas of concern emerge, in particular most of Tigray and large parts of Amhara, as well as an axis along the Rift Valley from Dire Dawa, over Oromia, to SNNPR. However, if we limit the analysis to Zn-deficient children on Zn-deficient soils (Fig. 6, Panel C), the areas of interest are much reduced, and mostly limited to five distinct geographical areas: eastern Tigray, southern Amhara, central and northeastern Oromia and southeastern SNNPR. The main reason for the reduction is the lower population density in areas with $\mathrm{Zn}$-deficient soils.

The data from these maps were then aggregated to calculate the number of $\mathrm{Zn}$-deficient children on the three soil categories, and for each region (Table 2). The results show that out of the 13 million Ethiopian CU5, 

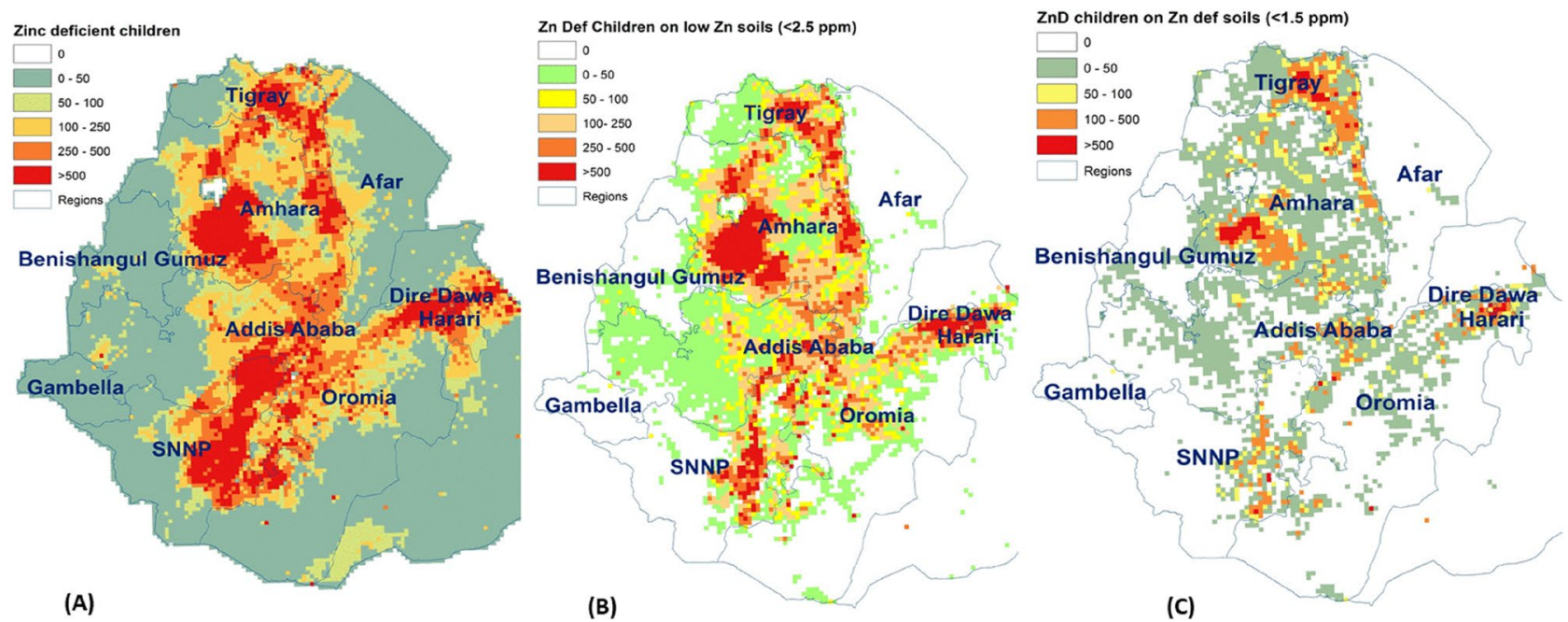

Figure 6. Mapping the number of zinc-deficient children, by zinc soil type (map produced with ArcGIS Desktop version 10.8.1 from ESRI, https://www.esri.com/en-us/arcgis/products/arcgis-desktop/overview).

\begin{tabular}{|c|c|c|c|c|c|c|c|c|c|c|c|}
\hline & \multicolumn{3}{|c|}{\begin{tabular}{|l|} 
Children under five \\
\end{tabular}} & \multicolumn{8}{|c|}{ Zinc deficient children under five } \\
\hline & \multirow[b]{3}{*}{ All } & \multicolumn{2}{|c|}{ On low Zn soils with crops } & \multirow{2}{*}{\multicolumn{4}{|c|}{ All, from ENMS }} & \multirow{2}{*}{\multicolumn{2}{|c|}{ 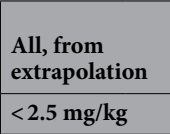 }} & \multirow{2}{*}{\multicolumn{2}{|c|}{$\begin{array}{l}\begin{array}{l}\text { On low } \mathrm{Zn} \\
\text { soils with } \\
\text { crops }\end{array} \\
<1.5 \mathrm{mg} / \mathrm{kg} \\
\end{array}$}} \\
\hline & & \multirow[b]{2}{*}{$<2.5 \mathrm{mg} / \mathrm{kg}$} & \multirow[b]{2}{*}{$<1.5 \mathrm{mg} / \mathrm{kg}$} & & & & & & & & \\
\hline & & & & $\mathbf{N}$ & $\%$ & $\mathbf{N}$ & $\%$ & $\mathbf{N}$ & $\%$ & $\mathbf{N}$ & $\%$ \\
\hline Tigray & 780,757 & 407,489 & 197,379 & 281,073 & 36 & 291,799 & 37 & 147,974 & 36 & 75,722 & 38 \\
\hline Afar & 255,676 & 5572 & 4886 & 102,270 & 40 & 94,332 & 37 & 1371 & 25 & 998 & 20 \\
\hline Amhara & $3,412,420$ & $2,173,250$ & 345,247 & $1,023,726$ & 30 & $1,124,970$ & 33 & 721,003 & 33 & 119,625 & 35 \\
\hline Benishangul Gumuz & 123,717 & 29,137 & 6359 & 24,743 & 20 & 14,897 & 12 & 7145 & 25 & 1452 & 23 \\
\hline Oromia & $4,694,730$ & $1,639,390$ & 238,066 & $1,173,683$ & 25 & $1,213,720$ & 26 & 388,088 & 24 & 64,104 & 27 \\
\hline Somali & 754,297 & 26,084 & 7748 & 181,031 & 24 & 276,460 & 37 & 8425 & 32 & 2107 & 27 \\
\hline Dire Dawa & 73,982 & 5,209 & 1795 & 21,455 & 29 & 35,921 & 49 & 1956 & 38 & 1091 & 61 \\
\hline Harari & 36,500 & 14,548 & 8225 & 11,680 & 32 & 3475 & 10 & 3870 & 27 & 2624 & 32 \\
\hline Addis Ababa & 587,807 & 61,555 & 10,014 & 352,684 & 60 & 204,369 & 35 & 13,426 & 22 & 2388 & 24 \\
\hline SNNPR & $2,618,460$ & 546,970 & 72,000 & 759,353 & 29 & $1,045,530$ & 40 & 198,904 & 36 & 32,858 & 46 \\
\hline \multirow[t]{2}{*}{ Gambella } & 44,657 & 4,296 & 4230 & 5805 & 13 & 9290 & 21 & 1009 & 23 & 880 & 21 \\
\hline & $13,383,003$ & $4,913,499$ & 895,950 & $3,937,504$ & 28 & $4,314,763$ & 32 & $1,493,172$ & 30 & 303,849 & 34 \\
\hline
\end{tabular}

Table 2. Number of children under five years of age, total and zinc deficient, living on zinc deficient and low zinc soils, by region.

about five million (37\%) live on low-Zn soils, and less than one million (7\%) on $\mathrm{Zn}$-deficient soils. The regions with the highest number of children on Zn-deficient soils are Amhara $(345,000)$, Oromia $(238,000)$ and Tigray (almost 200,000).

The ENMS averages, by region, find the highest levels of Zn deficiency among children under five in Afar (40\%), Tigray (36\%), Addis Ababa (60\%) and Harari (32\%), with a national average of $28 \%$. As these results are representative for the regions, these averages can be multiplied by the number of CU5. The results show that the largest number of $\mathrm{Zn}$-deficient under-fives are found in Oromia (1.2 million), Amhara (1.0 million), and SNNPR (0.8 million). Similar results were obtained by multiplying the grid with the probability of $\mathrm{Zn}$ deficiency, with the grid with the number of under-fives, albeit with a slightly higher estimate of the total proportion of deficient children (32\%).

Using the grid levels instead of regional averages, however, has the advantage that the number of $\mathrm{Zn}$-deficient children can now be calculated per soil type. The results show almost 1.5 million $\mathrm{Zn}$-deficient children on low- $\mathrm{Zn}$ soils, mostly in Amhara (0.72 million), Oromia (0.39 M), SNNPR (0.20 M) and Tigray (0.15 M). On Zn-deficient soils, on the other hand, we only find a low number of $\mathrm{Zn}$-deficient children, $0.3 \mathrm{M}$ in total, most of whom are in Amhara (120 k), Tigray (76 k), Oromia (64 k) and SNNPR (33 k). 


\section{Discussion}

This paper set out to explore the link between soil zinc deficiency and human zinc deficiency using two nationally representative data sets, the Ethiopian soil Zn map and the ENMS, and to quantify the potential for Zn fertilizers to improve human $\mathrm{Zn}$ deficiency. The soil map shows a clear pattern of $\mathrm{Zn}$-deficient soils located in the lower altitudes of Ethiopia, which have lower population density and less crop production. The lack of coincidence of $\mathrm{Zn}$ deficient soils, high population, and high levels of crop production raises the question of whether ZAB can have significant impact on human nutrition or health in Ethiopia. Meanwhile, the ENMS data show high levels of $\mathrm{Zn}$ deficiency among children and women, but without clear geographic patterns.

Combining the two data sets produces two main results. First, statistical analysis shows a significant, albeit small, association between soil $\mathrm{Zn}$ and serum $\mathrm{Zn}$ and $\mathrm{Zn}$ deficiency in children, but not in women. While this relationship is based on observational data and does not provide causal evidence, it does motivate further examination of the potential for ZAB to improve the nutritional status and health of young children. However, our calculations indicate that only about 300,000 Zn-deficient CU5 live on Zn-deficient soils in agricultural areas. If $\mathrm{Zn}$ fertilizers are only applied to $\mathrm{Zn}$-deficient soils, i.e., soils with inadequate $\mathrm{Zn}$ for crop growth, any potential impact would be limited to those children, and large investments in soil $\mathrm{Zn}$ fertilizers to improve human health may not be justified. Further agronomic research is needed to establish whether $\mathrm{Zn}$ fertilizer applied to soils with higher $\mathrm{Zn}$ levels will still increase grain $\mathrm{Zn}$ levels for the benefit of consumers. If so, Zn-deficient children who live on more fertile soils may benefit. Our calculations show, for example, that if $\mathrm{Zn}$ fertilizer could increase $\mathrm{Zn}$ grain levels not just on Zn-deficient soils ( $<1.5 \mathrm{mg} / \mathrm{kg}$ ) but also on low-Zn soils (from 1.5 to $2.5 \mathrm{mg} / \mathrm{kg}$ ), almost 1.5 million $\mathrm{Zn}$-deficient children could be reached. However, even if $\mathrm{Zn}$ fertilizers are effective in increasing grain $\mathrm{Zn}$ on non-Zn deficient soils ${ }^{51}$, significant changes in agricultural policies and practices would be needed before $\mathrm{Zn}$ fertilizers are used only for biofortification, without an agronomic need or yield benefit, and it is not clear who would shoulder the associated additional costs.

The second main result is that significant reduction in the prevalence of $\mathrm{Zn}$ deficiency in young children was only observed at high soil Zn levels. Even with a causal effect of soil Zn on children's Zn status, a key question remains on whether the amount of $\mathrm{Zn}$ fertilizer applied would result in an increase in soil fertility adequate to ultimately achieve reduced risk of human Zn deficiency. This finding suggests that the minimum adequate soil zinc level for human nutrition could be substantially higher than that for plants. Unfortunately, our data are too limited to calculate this minimum, and this value will likely vary by target population and context, depending on the severity of human zinc deficiency, other available dietary sources of Zn, soil properties that affect crops' Zn uptake, and other factors.

While $\mathrm{Zn}$ deficiency is an important public health problem, assessment of $\mathrm{Zn}$ status poses technical challenges $^{55,56}$. Zinc in serum or plasma, despite its limitations, is the recommended biomarker, and linear growth (height-for-age) in CU5 is the only recommended functional indicator, hence the usage of these measures in this paper. Our estimates of $\mathrm{Zn}$ deficiency based on serum $\mathrm{Zn}$ are much lower than those based on food consumption ${ }^{25,26}$. As the Ethiopian soil map is available online and in the public domain, the present study can easily be expanded to other biomarkers or other indicators of $\mathrm{Zn}$ deficiency that are georeferenced. However, such data are not likely to be widely available and representative of a target population, complicating analysis of the wider potential nutritional and health effects of $Z A B$ across the life course.

An alternative or complementary option to soil $\mathrm{Zn}$ fertilizers would be foliar $\mathrm{Zn}$ applications. These have only a small or no effect on yields on Zn deficient soils, as compared to soil Zn applications; however, foliar Zn applications increase grain $\mathrm{Zn}$ across a range of soil $\mathrm{Zn}$ levels and do so more efficiently than soil $\mathrm{Zn}$ applications ${ }^{43,51,57}$. This efficiency varies by crop and soil type, which in turn vary by altitude. On wheat, grown in the higher altitudes of Ethiopia, soil Zn applications on Zn deficient soils increase grain yields, but foliar applications do not ${ }^{43,57}$. Similar results were found on peas ${ }^{58}$. Meanwhile, foliar applications on maize (usually grown at altitudes lower than for wheat) and barley (grown at higher altitudes) did increase yields ${ }^{59,60}$. In maize, a small yield effect was found from foliar spray in pot trials, but a larger effect from soil application, and the highest with the combination ${ }^{60}$; for grain $\mathrm{Zn}$, on the other hand, foliar application had a stronger effect than soil application, and again the highest levels were obtained with a combination. In barley, a positive effect of foliar spray on both yield and grain $\mathrm{Zn}$ was found ${ }^{59}$. Rice, a low-land crop, appears to respond similar to wheat: $\mathrm{Zn}$ fertilizer had little effect on rice grain yield, but increased grain $\mathrm{Zn}^{61}$.

On the positive side, as zinc fertilizer can increase grain zinc in both wheat ${ }^{51}$ and maize ${ }^{62}$ on soils that are not zinc-deficient, the impact of zinc fertilizer on human health can go beyond its use on zinc-deficient soils. We do not know at this stage how far, but the Geonutrition Project ${ }^{63}$ is conducting studies aiming to find the critical level of soil zinc to meet human nutrition needs. As we show here, if zinc fertilizer is effective on low-zinc soils, one and a half million zinc-deficient children could be reached. It should be further noted that our cutoff to indicate low soil zinc $(2.5 \mathrm{mg} / \mathrm{kg})$ is arbitrary, as currently we do not have an empirical basis for such a limit. On the negative side, this would mean that zinc fertilizer on low-zinc soils might not increase crop yields. With no increase in yield, a farmer would not benefit from use of zinc fertilizer, and the extra cost of that fertilizer would therefore need to be covered by subsidies. The farmer could benefit if there were a premium for biofortified grain; however, this is unlikely as grain biofortified with zinc cannot be easily distinguished from non-biofortified grain, and in this scenario, any benefit would be monetary rather than nutritional for the farming household. Hence, the cost effectiveness of agronomic biofortification needs to be compared to other interventions such as genetic biofortification, as has been argued before ${ }^{46}$. As the effects of soil nutrients on human health in Africa have been found to be fairly small, agronomic biofortification might not be the most cost-effective way to reduce malnutrition, except for a few regions ${ }^{47}$.

The fertilizer blending initiative in Ethiopia provides a good opportunity to add $\mathrm{Zn}$ to soil fertilizer, which would increase crop yield on $\mathrm{Zn}$ deficient soils, but would only have a small effect on grain $\mathrm{Zn}$, and only on 
those soils. As our results show the relatively lower cultivation of crops on $\mathrm{Zn}$ deficient soils, the impact could be small. As we describe above, foliar sprays are an alternative or complementary strategy to increase grain $\mathrm{Zn}$, even on soils that are not $\mathrm{Zn}$ deficient, but they would have little or no effect on grain yields ${ }^{43,51}$. Therefore, foliar sprays should be considered in an overall biofortification strategy, in combination with the best crop varieties ${ }^{43}$. However, unlike soil $\mathrm{Zn}$ application, in which $\mathrm{Zn}$ can just be added in a fertilizer blending facility, foliar spray requires a very different approach and the involvement of farmers in application. To find the optimal strategy, more experiments are needed across crops and target environments, along with careful economic analysis.

For an integrated strategy, both genetic and agronomic fortification will probably be needed ${ }^{43,64,65}$. Genetic biofortification is sustainable and cost-effective to increase grain $\mathrm{Zn}^{36,44}$. While genetic variation of $\mathrm{Zn}$ concentration is lower in grain than in leaves, it still has sufficient variation for breeding ${ }^{66}$. However, it is a long-term process requiring substantial efforts and resources; while foliar or combined soil and foliar application of $\mathrm{Zn}$ fertilizers offer highly effective and practical short-term solutions ${ }^{44}$. Moreover, while this will help with micronutrient deficiencies, other measures are needed to solve the wider food insecurity problem in Ethiopia ${ }^{67}$.

In conclusion, our study confirms that $\mathrm{Zn}$ deficiency is a serious public health problem in Ethiopia, as has been shown in other countries ${ }^{30}$, and that it is related to low soil $\mathrm{Zn}$, as we had shown earlier ${ }^{49}$. We expanded that analysis by calculating the potential impact in terms of the number of $\mathrm{Zn}$-deficient children that could be reached. This strengthens the evidence on the potential of $\mathrm{ZAB}^{7}$. However, we also show that, in Ethiopia, the main agricultural soils are not $\mathrm{Zn}$-deficient, and as the human population is concentrated on those soils, the potential impact of $\mathrm{Zn}$ fertilizer on $\mathrm{Zn}$-deficient soils, at least by soil application, is limited. However, if grain $\mathrm{Zn}$ could be increased through $\mathrm{Zn}$ fertilizer on less deficient soils, through soil or especially foliar application, the potential could be much larger, depending on the maximum soil $\mathrm{Zn}$ level up to which $\mathrm{Zn}$ fertilizer is effective in increasing grain $\mathrm{Zn}$. More experimental work is needed to determine that maximum level, to calculate the total area for which $\mathrm{Zn}$ fertilizer would be effective, and to calculate the associated cost of Zn agronomic biofortification through both soil and foliar applications. From there, the potential impact in terms of the number of $\mathrm{Zn}$-deficient children that could be reached can be calculated.

Received: 23 November 2020; Accepted: 7 April 2021

Published online: 22 April 2021

\section{References}

1. Black, R. E. Consequences of zinc deficiency on human health and alternatives for programmatic intervention. In Public health issues in infant and child nutrition. Nestlé Nutrition Workshop Series, Pediatric Program Vol. 48 (eds Black, R. E. \& Michaelsen, K. F.) (Nestec Ltd., Vevey/Lippincott William \& Wilkins, Philadelphia, 2002).

2. Black, R. E. et al. Maternal and child undernutrition: Global and regional exposures and health consequences. The Lancet 371, 243-260 (2008).

3. Black, R. E. Zinc deficiency, infectious disease and mortality in the developing world. J. Nutr. 133, 1485S-1489S (2003).

4. Black, R. E. Therapeutic and preventive effects of zinc on serious childhood infectious diseases in developing countries. Am. J. Clin. Nutr. 68(suppl 2), 476S-479S (1998).

5. Roohani, N., Hurrell, R., Kelishadi, R. \& Schulin, R. Zinc and its importance for human health: An integrative review. J. Res. Med. Sci. 18(2), 144-157 (2013).

6. Hengl, T. et al. Soil nutrient maps of Sub-Saharan Africa: Assessment of soil nutrient content at $250 \mathrm{~m}$ spatial resolution using machine learning. Nutr. Cycl. Agroecosyst. 109(1), 77-102. https://doi.org/10.1007/s10705-017-9870-x (2017).

7. Joy, E. J. M. et al. Zinc-enriched fertilisers as a potential public health intervention in Africa. Plant Soil 389(1), 1-24. https://doi. org/10.1007/s11104-015-2430-8 (2015).

8. Cakmak, I. \& Kutman, U. B. Agronomic biofortification of cereals with zinc: a review. Eur. J. Soil Sci. 69(1), 172-180. https://doi. org/10.1111/ejss.12437 (2018).

9. Bouis, H. E. \& Saltzman, A. Improving nutrition through biofortification: A review of evidence from HarvestPlus, 2003 through 2016. Glob. Food Secur. 12(2017), 49-58. https://doi.org/10.1016/j.gfs.2017.01.009 (2003).

10. Alloway, B. J. Soil factors associated with zinc deficiency in crops and humans. Environ. Geochem. Health 31(5), 537-548 (2009).

11. Prasad, A. S., Halsted, J. A. \& Nadimi, M. Syndrome of iron deficiency anemia, hepatosplenomegaly, hypogonadism, dwarfism, and geophagia. Am. J. Med. 31, 532-546 (1961).

12. Prasad, A. S. Zinc deficiency in humans: A neglected problem. J Am Coll Nutr. 17(6), 542-543 (1998).

13. Imdad, A. \& Bhutta, Z. Effect of preventive zinc supplementation on linear growth in children under 5 years of age in developing countries: A meta-analysis of studies for input to the lives saved tool. BMC Public Health 11(Suppl 3), S22 (2011).

14. Yakoob, M. Y. et al. Preventive zinc supplementation in developing countries: Impact on mortality and morbidity due to diarrhea, pneumonia and malaria. BMC Public Health 11(Suppl 3), S23 (2011).

15. Shankar, A. H. \& Prasad, A. S. Zinc and immune function: The biological basis of altered resistance to infection. Am. J. Clin. Nutr. 68(2), 447S-463S. https://doi.org/10.1093/ajcn/68.2.447S (1998).

16. Graham, R., Ascher, J. \& Hynes, S. Selecting zinc-efficient cereal genotypes for soils of low zinc status. Plant Soil 146(1-2), 241-250. https://doi.org/10.1007/BF00012018 (1992).

17. Alloway, B. J. Zinc in Soils and Crop Nutrition (International Zinc Association, 2004).

18. Shiferaw, H. Tigray Region's Soil Fertility Status and New Fertilizer Recommendation. Paper presented at a seminar at ATA, October 24, 2014. The Ethiopia Strategy Support Program and the Ethiopian Development Research Institute, Addis Ababa (2014).

19. T.M. Staff, Zinc, 2020.

20. Wessells, K. R. \& Brown, K. H. Estimating the global prevalence of zinc deficiency: results based on zinc availability in national food supplies and the prevalence of stunting. PLoS ONE 7(11), e50568 (2012).

21. Supasai, S., Aimo, L., Adamo, A. M., Mackenzie, G. G. \& Oteiza, P. I. Zinc deficiency affects the STAT1/3 signaling pathways in part through redox-mediated mechanisms. Redox Biol. 11, 469-481. https://doi.org/10.1016/j.redox.2016.12.027 (2017).

22. Danaei, G. et al. Risk factors for childhood stunting in 137 developing countries: A comparative risk assessment analysis at global, regional, and country levels. PLoS Med. 13(11), e1002164 (2016).

23. Gibson, R. S., Bailey, K. B., Gibbs, M. \& Ferguson, E. L. A review of phytate, iron, zinc, and calcium concentrations in plant-based complementary foods used in low-income countries and implications for bioavailability. Food Nutr. Bull. 31(2 Suppl), S134-S146. https://doi.org/10.1177/15648265100312s206 (2010).

24. Gibson, R. S. A historical review of progress in the assessment of dietary zinc intake as an indicator of population zinc status. Adv. Nutr. 3(6), 772-782. https://doi.org/10.3945/an.112.002287 (2012). 
25. Samuel, A. Overview of Ethiopian Food Consumption Survey: Implications for Food Fortification Program. Ethiopian Public Health Institute, 3rd Micronutrient Forum Global Conference, Addis Ababa (2014).

26. CSA, ICF, Ethiopia Demographic and Health Survey 2011, Central Statistical Agency (CSA) Ethiopia and ICF International, Addis Ababa, Ethiopia, and Calverton, Maryland, USA (2012).

27. $\mathrm{MOH}$, Health and Health Related Indicators, Planning and Programming Department, the Ministry of Health (MOH), Addis Ababa, Ethiopia (2004).

28. Umeta, M. Role of zinc in stunting of infants and children in rural Ethiopia, Division of Human Nutrition and Epidemiology Wageningen University, Wageningen, The Netherlands, 120 (2003).

29. Umeta, M., West, C. E., Haider, J., Deurenberg, P. \& Hautvast, J. G. Zinc supplementation and stunted infants in Ethiopia: A randomized control trail. Lancet 355, 2021-2026 (2000).

30. Caulfield, L. E. \& Black, R. E. Zinc deficiency. In Comparative Quantification of Health Risks Global and Regional Burden of Disease Attributable to Selected Major Risk Factors Vol. I (eds Ezzati, M. et al.) 257-279 (World Health Organization, Geneva, 2004).

31. EPHI, Ethiopia National Micronutrient Survey Report, Ethiopian Public Health Institute, Addis Ababa (2016).

32. Gibbs, M., Wuehler, S., \& Samuel, A. National Food Fortification Simulations. Ethiopia: Sub-report of the National Food Consumption Survey, 2011, Addis Ababa, Ethiopia (2013)

33. Nestel, P., Bouis, H. E., Meenakshi, J. V. \& Pfeiffer, W. Biofortification of staple food crops. J. Nutr. 136, 1064-1067 (2006).

34. White, P. J. \& Broadley, M. R. Biofortification of crops with seven mineral elements often lacking in human diets-Iron, zinc, copper, calcium, magnesium, selenium and iodine. New Phytol. 182(1), 49-84. https://doi.org/10.1111/j.1469-8137.2008.02738.x (2009).

35. Bouis, H. E. Economics of enhanced micronutrient density in food staples. Field Crop Res. 60(1-2), 165-173 (1999).

36. Meenakshi, J. V. et al. How cost-effective is biofortification in combating micronutrient malnutrition? An ex ante assessment. World Dev. 38(1), 64-75 (2010).

37. Low, J. W. et al. A food-based approach introducing orange-fleshed sweet potatoes increased vitamin A intake and serum retinol concentrations in young children in rural mozambique. J. Nutr. 137(5), 1320-1327 (2007).

38. Nuss, E. T. \& Tanumihardjo, S. A. Maize: A paramount staple crop in the context of global nutrition. Compr. Rev. Food Sci. Food Saf. 9(4), 417-436 (2010).

39. Bouis, H. E., Hotz, C., McClafferty, B., Meenakshi, J. V. \& Pfeiffer, W. H. Biofortification: A new tool to reduce micronutrient malnutrition. Food Nutr. Bull. 32(Supplement 1), 31S-40S (2011).

40. Cakmak, I., Pfeiffer, W. H. \& McClafferty, B. Biofortification of durum wheat with zinc and iron. Cereal Chem. 87(1), 10-20 (2010).

41. Alfthan, G. et al. Effects of nationwide addition of selenium to fertilizers on foods, and animal and human health in Finland: From deficiency to optimal selenium status of the population. J. Trace Elem. Med Biol. 31, 142-147. https://doi.org/10.1016/j.jtemb.2014. 04.009 (2015).

42. Koivistoinen, P. \& Huttunen, J. K. Selenium in food and nutrition in Finland. An overview on research and action. Ann. Clin. Res. 18(1), 13-17 (1986).

43. Cakmak, I. et al. Biofortification and localization of zinc in wheat grain. J. Agric. Food Chem. 58(16), 9092-9102. https://doi.org/ 10.1021/jf101197h (2010).

44. Cakmak, I. Enrichment of cereal grains with zinc: Agronomic or genetic biofortification?. Plant Soil 302(1-2), 1-17. https://doi. org/10.1007/s11104-007-9466-3 (2008).

45. Cakmak, I. \& Kutman, U. B. Agronomic biofortification of cereals with zinc: A review. Eur. J. Soil Sci. 1, 5. https://doi.org/10.1111/ ejss.12437 (2018).

46. De Valença, A., Bake, A., Brouwer, I. \& Giller, K. Agronomic biofortification of crops to fight hidden hunger in sub-Saharan Africa. Glob. Food Sec. 12, 8-14 (2017)

47. Berkhout, E. D., Malan, M. \& Kram, T. Better soils for healthier lives? An econometric assessment of the link between soil nutrients and malnutrition in Sub-Saharan Africa. PLoS ONE 14(1), e0210642 (2019).

48. Sunanda, L., Sumathi, S. \& Venkatasubbaiah, V. Relationship between soil zinc, dietary zinc and zinc nutritional status of humans. Plant Foods Hum. Nutr. (Formerly Qualitas Plantarum) 48(3), 201-207 (1995).

49. Tessema, M. et al. Soil Zinc Is Associated with Serum Zinc But Not with Linear Growth of Children in Ethiopia. Nutrients 11(2), 221 (2019).

50. Gibson, R. S. Zinc: the missing link in combating micronutrient malnutrition in developing countries. Proc. Nutr. Soc. 65(1), 51-60. https://doi.org/10.1079/pns2005474 (2006).

51. Zou, C. Q. et al. Biofortification of wheat with zinc through zinc fertilization in seven countries. Plant Soil 361(1), 119-130. https:// doi.org/10.1007/s11104-012-1369-2 (2012)

52. Mehlich, A. Mehlich 3 soil test extractant: A modification of Mehlich 2 extractant. Commun. Soil Sci. Plant Anal. 15(12), 1409-1416 (1984).

53. Noulas, C., Tziouvalekas, M. \& Karyotis, T. Zinc in soils, water and food crops. J. Trace Elem. Med. Biol. 49, 252-260. https://doi. org/10.1016/j.jtemb.2018.02.009 (2018).

54. AfSIS, New cropland and rural settlement maps of Africa, 2015. http://africasoils.net/2015/06/07/new-cropland-and-rural-settl ement-maps-of-africa/. (accessed 26 January 2021, 2021).

55. IZiNCG, Assessing Population Zinc Status with Serum ZINC Concentration, ernational Zinc Nutrition Consultative Group (IZiNCG), Oakland, CA, USA (2012).

56. King, J. C. et al. Biomarkers of Nutrition for Development (BOND) -Zinc review. J. Nutr. 146(4), 858S-885S. https://doi.org/10. 3945/jn.115.220079 (2016)

57. Gomez-Coronado, F., Poblaciones, M. J., Almeida, A. S. \& Cakmak, I. Zinc (Zn) concentration of bread wheat grown under Mediterranean conditions as affected by genotype and soil/foliar Zn application. Plant Soil 401(1-2), 331-346 (2016).

58. Poblaciones, M. J. \& Rengel, Z. Soil and foliar zinc biofortification in field pea (Pisum sativum L.): Grain accumulation and bioavailability in raw and cooked grains. Food Chem. 212, 427-433. https://doi.org/10.1016/j.foodchem.2016.05.189 (2016).

59. Gonzalez, D., Almendros, P., Obrador, A. \& Alvarez, J. M. Zinc application in conjunction with urea as a fertilization strategy for improving both nitrogen use efficiency and the zinc biofortification of barley. J. Sci. Food Agric. 99(9), 4445-4451. https://doi.org/ $10.1002 /$ isfa.9681 (2019).

60. Imran, M. \& Rehim, A. Zinc fertilization approaches for agronomic biofortification and estimated human bioavailability of zinc in maize grain. Arch. Agron. Soil Sci. 63(1), 106-116. https://doi.org/10.1080/03650340.2016.1185660 (2017).

61. Phattarakul, N. et al. Biofortification of rice grain with zinc through zinc fertilization in different countries. Plant Soil 361(1-2), 131-141 (2012).

62. Manzeke, G. M., Mtambanengwe, F., Nezomba, H. \& Mapfumo, P. Zinc fertilization influence on maize productivity and grain nutritional quality under integrated soil fertility management in Zimbabwe. Field Crops Res. 166, 128-136. https://doi.org/10. 1016/j.fcr.2014.05.019 (2014).

63. Geonutrition. www.geonutrition.org (2019).

64. Kodkany, B. S. et al. Biofortification of pearl millet with iron and zinc in a randomized controlled trial increases absorption of these minerals above physiologic requirements in young children. J. Nutr. 143(9), 1489-1493 (2013).

65. Sazawal, S. et al. Efficacy of high zinc biofortified wheat in improvement of micronutrient status, and prevention of morbidity among preschool children and women-a double masked, randomized, controlled trial. Nutr. J. 17(1), 1-10 (2018). 
66. White, P. \& Broadley, M. Physiological Limits to Zinc Biofortification of Edible Crops. Front. Plant Sci. 2, 80. https://doi.org/10. 3389/fpls.2011.00080 (2011).

67. Stifel, D. \& Hassen, I. W. Food security, IFPRI book chapters 299-339 (2020).

\section{Acknowledgements}

We thank the Ethiopian Public Health Institute (EPHI) for making available the ENMS data, and Marcus Walsh of AfSIS for making available soil data. Finally, we thank the households who participated in the ENMS, and especially the chidren who literally gave their blood to make this study possible. The authors thank the Bill and Melinda Gates Foundation and the United Kingdom Department for International Development (DfID) for supporting this study (Global Development Grant Number OPP1130181).

\section{Author contributions}

H.D.G. and N.S.G. designed the study and wrote the original draft of the manuscript; H.D.G., N.S.G. and S.G. acquired funding; HDG managed the project, conducted the GIS analysis and produced the maps; M.T. provided background information, curated and analyzed the ENMS data; S.G. provided background information and analyzed the soil data; all authors read and commented on the final draft.

\section{Competing interests}

The authors declare no competing interests.

\section{Additional information}

Correspondence and requests for materials should be addressed to H.G.

Reprints and permissions information is available at www.nature.com/reprints.

Publisher's note Springer Nature remains neutral with regard to jurisdictional claims in published maps and institutional affiliations.

(c) (1) Open Access This article is licensed under a Creative Commons Attribution 4.0 International License, which permits use, sharing, adaptation, distribution and reproduction in any medium or format, as long as you give appropriate credit to the original author(s) and the source, provide a link to the Creative Commons licence, and indicate if changes were made. The images or other third party material in this article are included in the article's Creative Commons licence, unless indicated otherwise in a credit line to the material. If material is not included in the article's Creative Commons licence and your intended use is not permitted by statutory regulation or exceeds the permitted use, you will need to obtain permission directly from the copyright holder. To view a copy of this licence, visit http://creativecommons.org/licenses/by/4.0/.

(c) The Author(s) 2021 